\title{
Miller and Payne Classification
}

National Cancer Institute

\section{Source}

National Cancer Institute. Miller and Payne Classification. NCI Thesaurus. Code C63611.

A classification system for grading pathological remission based purely on microscopic assessment. It classifies patients into five groups with significantly different disease-free and overall survival and grades pathological remission in both the primary tumor and the axillary lymph nodes, with comparison of negative nodes with those that have already responded to chemotherapy. 